\title{
WIDEBAND MICROSTRIP ANTENNA USING PARASITIC PATCH ELEMENT
}

\author{
Susmita Bala \\ Department of Electronics, Vidyasagar University, Midnapore 721102, West Bengal, India
}

\begin{abstract}
A wideband microstrip antenna using parasitic patch element is proposed in this paper. Initially a circular patch antenna is designed. The antenna is found to resonate at $5.2 \mathrm{GHz}$ and provides impedance bandwidth of 3.84\%. To enhance the impedance bandwidth, two unequal rectangular parasitic patches are introduced along with the modified initial circular patch antenna which provides impedance bandwidth which ranges from $7.86 \mathrm{GHz}$ to $10.60 \mathrm{GHz}$ with $29.68 \%$ of impedance bandwidth . Suitable peak gain of $4.56 \mathrm{dBi}$ is also achieved by the proposed antenna. This makes the antenna suitable for $X$ band $(8-10 \mathrm{GHz})$ application.
\end{abstract}

Keyword: coupling, gain, parasitic patch, resonate frequency, wideband

Cite this Article: Susmita Bala, Wideband Microstrip Antenna Using Parasitic Patch Element, International Journal of Advanced Research in Engineering and Technology, 10(2), 2019, pp 564-570.

http://iaeme.com/Home/issue/IJARET?Volume=10\&Issue $=2$

\section{INTRODUCTION}

The demand of small size wideband antenna is increasing day by day with the rapid development of wireless communication systems. Microstrip patch antenna is a popular candidate to satisfy these criteria. Microstrip patch antennas have several advantages mentioned by Girish Kumar and K.P Ray [1]. They are low profile, light weight, low volume, low fabrication cost, supports both linear and circular polarization, can be easily integrated with microwave integrated circuits (MICs) and capable of dual and triple frequency operations etc but it has the limitation of narrow bandwidth. Many techniques have been reported previously to overcome its limitations for example CPW feed technique[2-3], using monopole antenna[46], applying defected ground structure[7] using different slots on radiating patch[8] and using rectangular radiating patch with parasitic patch [9] etc.

In this paper a modified circular patch antenna with two parasitic patch elements is presented to widen the bandwidth. Proposed antenna provides impedance bandwidth ranging from $7.86 \mathrm{GHz}$ to $10.60 \mathrm{GHz}$. Satisfied gain and radiation patterns are also achieved.

\section{ANTENNA DESIGN}

The constructional details of the antennas are illustrated in this section. The antennas are designed and simulated by Ansoft Designer V2 software. 


\subsection{ANTENNA I}

Design of Antenna I is discussed in this subsection. Antenna I consists of a circular radiating patch. In the design procedure of the Antenna I, the desired resonant frequency, thickness and dielectric constant of the substrate are selected initially. In this design of circular microstrip antenna, low cost FR4 substrate with dielectric constant 4.4, height $1.6 \mathrm{~mm}$ and tan $\delta=.02$ is selected. A single element of circular patch antenna, as shown in figure 1(a), is designed for the $5.2 \mathrm{GHz}$ resonant frequency using cavity model equation (1)[10],

$$
\mathrm{Fr}=1.8412 \mathrm{Vo} / 2 \pi \mathrm{a} \sqrt{ } \mu \varepsilon .
$$

Where $F r=$ resonant frequency,

Vo is the velocity of light in free space,

$\mathrm{a}=$ radius of circular patch,

$\mu=$ permeability of the medium

and $\varepsilon=$ dielectric constant of the dielectric.

Using above mentioned equation the calculated radius is $8.1 \mathrm{~mm}$. After optimization the considered radius for Antenna I is $8.2 \mathrm{~mm}$. To achieve proper matching between antenna and coaxial probe, the antenna is excited by coaxial probe and the best feed position is chosen. Feed point location for Antenna I is indicated as small red colour box shown in Fig. I (a) and is given at table 1 where first coordinate indicate $\mathrm{x}$ axis and second coordinate indicate $\mathrm{y}$ axis.

\subsection{ANTENNA II}

The Antenna I is modified by etching of two unequal semi-circular patches from the left and right sides of the circular patch as shown in Fig. I (b) and it will be termed as Antenna II. This Antenna II has been approximated as rectangular patch of length $8.5 \mathrm{~mm}$ and width $13 \mathrm{~mm}$. The operating frequency has shifted to $8.3 \mathrm{GHz}$.

Straight side of microstrip antenna provides a better gap coupling between the patches as compared to that of the curved periphery of a circular microstrip antenna [11].That is why the Antenna II has been modified so that rectangular patch may be used as parasitic patch to enhance the coupling. The dimensions and feed point location of the Antenna II are listed at table1.

\subsection{ANTENNA III}

A rectangular patch of dimension $3 \mathrm{~mm} \times 19 \mathrm{~mm}$ is introduced at the right side of modified circular patch antenna (Antenna II) and thereby Antenna III is constructed is shown in Fig. I(c).The rectangular patch acts as a parasitic element with the modified circular patch. The gap between the modified circular patch and parasitic rectangular patch is taken as small as possible for the best coupling and after optimization the final gap of $0.5 \mathrm{~mm}$ has been found for the consideration. The dimensions and feed point location of the Antenna III are listed at TABLE.1

\subsection{ANTENNA IV (PROPOSED ANTENNA)}

An extra rectangular patch of $4 \mathrm{~mm} \times 19 \mathrm{~mm}$ is designed at the left side of the Antenna III and the gap between rectangular patch and main radiating element is $0.5 \mathrm{~mm}$ and Antenna IV is designed as shown in Fig. I (d). Here two unequal rectangular patches act as parasitic elements. The energy of main patch is coupled between the two parasitic patches and hence larger impedance bandwidth is obtained. The feed point location is chosen closer to the edge of the main radiating patch so as to achieve the best coupling and hence larger bandwidth is obtained. 


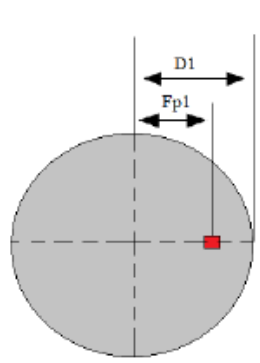

(a)

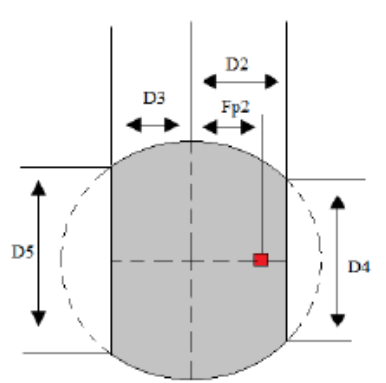

(b)

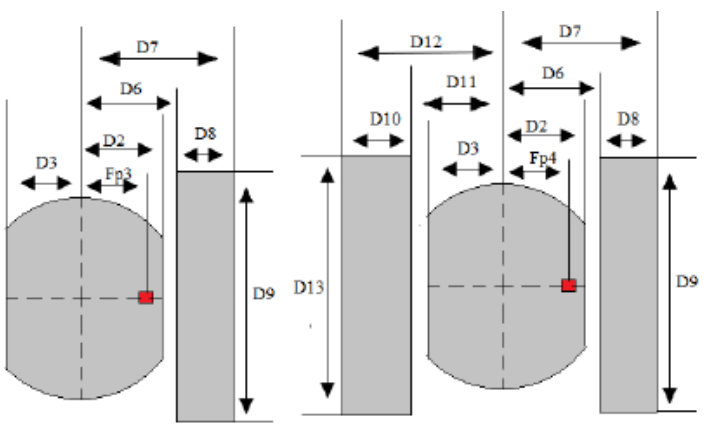

(c)

(d)

Figure. 1: Proposed Antenna Structure.

(a)Antenna I; (b) Antenna II; (c) Antenna III, and (d) Antenna IV

TABLE.1

Dimensions of the Antenna Structure

\begin{tabular}{|c|c|c|c|c|c|c|c|c|c|c|}
\hline D1 & D2 & D3 & D4 & D5 & D6 & D7 & D8 & D9 & D10 & D11 \\
\hline $8.2 \mathrm{~mm}$ & $5 \mathrm{~mm}$ & $3.5 \mathrm{~mm}$ & $13 \mathrm{~mm}$ & $18.8 \mathrm{~mm}$ & $5.5 \mathrm{~mm}$ & $8.5 \mathrm{~mm}$ & $3 \mathrm{~mm}$ & $19 \mathrm{~mm}$ & $4 \mathrm{~mm}$ & $4 \mathrm{~mm}$ \\
\hline D12 & D13 & Fp1 & Fp2 & Fp3 & Fp4 & & & & & \\
\hline $8 \mathrm{~mm}$ & $19 \mathrm{~mm}$ & $(2.5,0)$ & $(4,0)$ & $(4,0)$ & $(4,0)$ & & & & & \\
\hline
\end{tabular}

\section{RESULTS}

The simulated results of return loss, gain and radiation pattern of the Antenna I, Antenna II, Antenna III and Antenna IV are discussed in this section. The details of frequency versus return loss curve for all antennas are shown in Fig. II. Fig. II (a) shows the frequency versus return loss of Antenna I. The antenna resonates at $5.2 \mathrm{GHz}$ and simulated bandwidth is $200 \mathrm{MHz}$ and percentage of bandwidth is $3.84 \%$. The frequency versus return loss of Antenna II, Antenna III and Antenna IV are shown in Fig. II (b), Fig. II(c) and Fig. II (d) respectively. Antenna II provides two resonate frequencies of $8.3 \mathrm{GHz}$ and $9.7 \mathrm{GHz}$ with impedance bandwidth of 720 $\mathrm{MHz}$ and $440 \mathrm{MHz}$ respectively. Antenna II is an approximation to rectangular patch. Two frequency bands are obtained from Antenna III are shown in Fig. II(c). The two resonate frequencies are $8.2 \mathrm{GHz}$ and $9.8 \mathrm{GHz}$ and impedance bandwidths are $590 \mathrm{MHz}$ and $460 \mathrm{MHz}$ respectively. Finally with the introduction of two parasitic patches (Antenna IV) the impedance bandwidth of $2.74 \mathrm{GHz}(7.86 \mathrm{GHz}-10.60 \mathrm{GHz})$ is achieved by the proposed antenna which is $29.68 \%$ and is shown in Fig-II (d). Fig. II (e) shows the comparative study of frequency versus return loss of Antenna I, Antenna II, Antenna III and Antenna IV. Here it is shown that the resonant frequencies of Antenna II, Antenna III and Antenna IV have shifted at upper frequency range. This is due to the fact that the dimension of the main radiating patch of Antenna II, Antenna III and Antenna IV becomes smaller than initial patch (Antenna I). Frequency in GHz versus gain in $\mathrm{dBi}$ is shown in Fig III .Simulated gain of Antenna I is shown in Fig. III (a).The peak gain is $3.7 \mathrm{dBi}$ at $5.2 \mathrm{GHz}$. Fig. III (b) shows the gain of Antenna II. The peak gain is 4.42 $\mathrm{dBi}$. Antenna III provides peak gain of $4.4 \mathrm{dBi}$ is shown in Fig. III(c). The peak gain of $4.56 \mathrm{dBi}$ at $8.2 \mathrm{GHz}$ frequency is obtained from the Antenna IV and is shown in Fig. III (d). Radiation patterns of the antennas are shown in Fig. IV. Radiation pattern of Antenna I at $5.2 \mathrm{GHz}$ is shown in Fig. IV (a). Fig. IV (b) and Fig. IV(c) shows radiation patterns of Antenna II at 8.3 $\mathrm{GHz}$ and $9.7 \mathrm{GHz}$ respectively. Radiation patterns of Antenna III at $8.2 \mathrm{GHz}$ and $9.8 \mathrm{GHz}$ are shown in Fig. IV (d) and Fig. IV (e) respectively. Again radiation patterns of Antenna IV at 8.2 


\section{Susmita Bala}

$\mathrm{GHz}$ and $9.2 \mathrm{GHz}$ and $10.48 \mathrm{GHz}$ are shown in Fig. IV (f), Fig. IV (g) and Fig. IV (g) respectively.

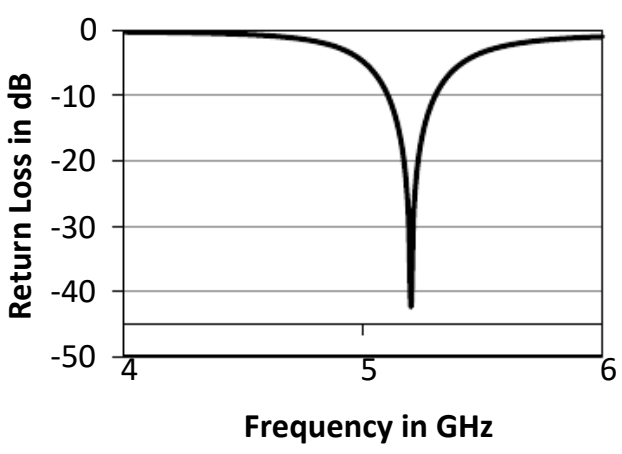

(a)

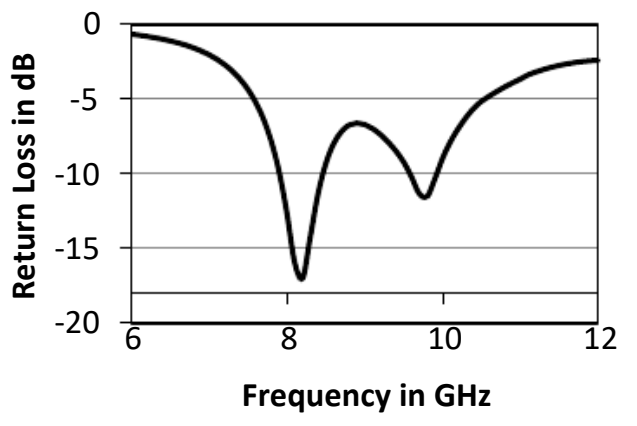

(c)

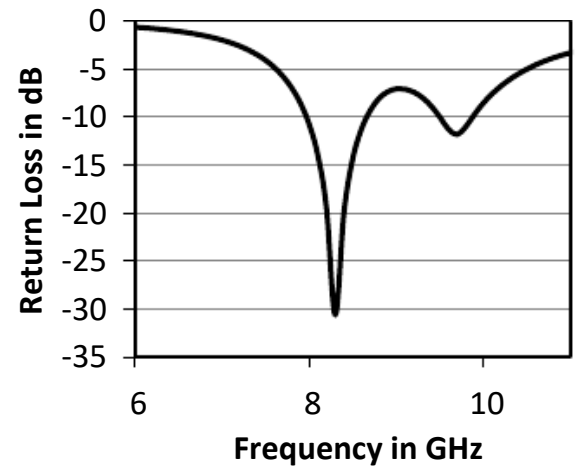

(b)

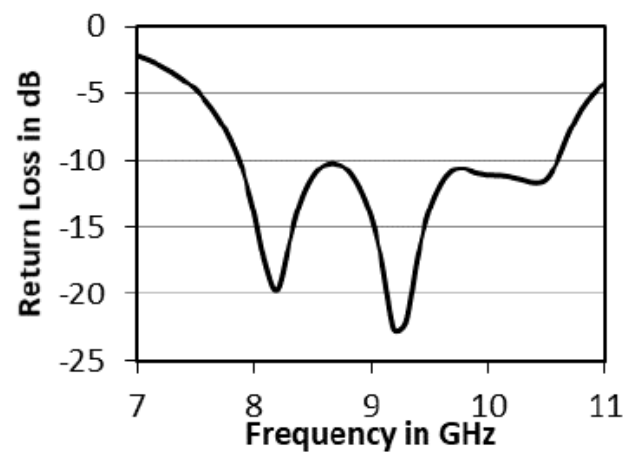

(d)

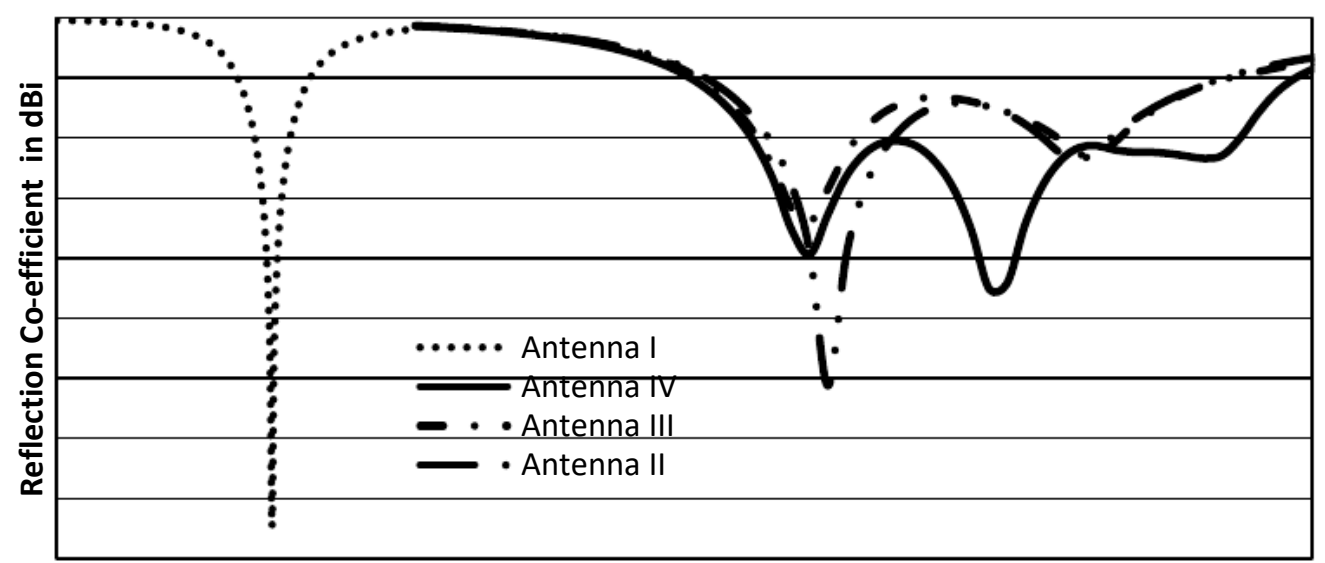

Frequency in $\mathrm{GHz}$

(e)

Figure. 2 Plot of frequency $(\mathrm{GHz})$ versus return loss $(\mathrm{dB})$.

(a) Antenna I; (b) Antenna II; (c) Antenna III; (d) Antenna IV; and (e) Comparative study of frequency versus return loss for Antenna I, Antenna II, Antenna III and Proposed Antenna. 
Wideband Microstrip Antenna Using Parasitic Patch Element

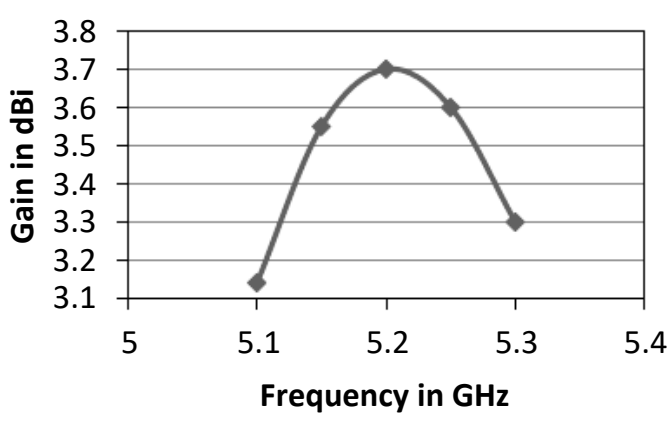

A

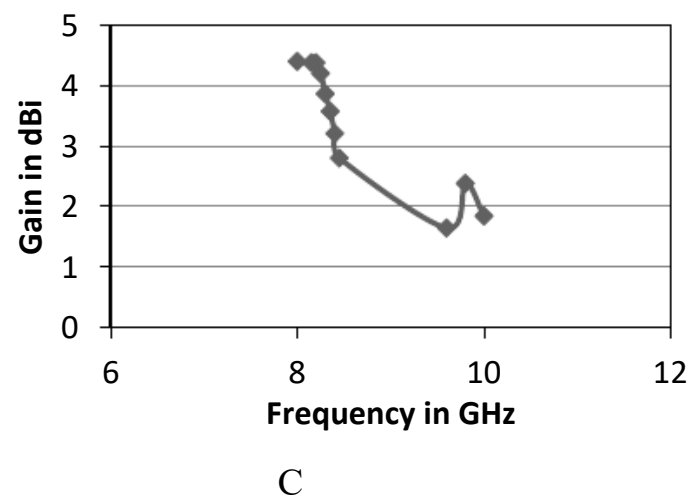

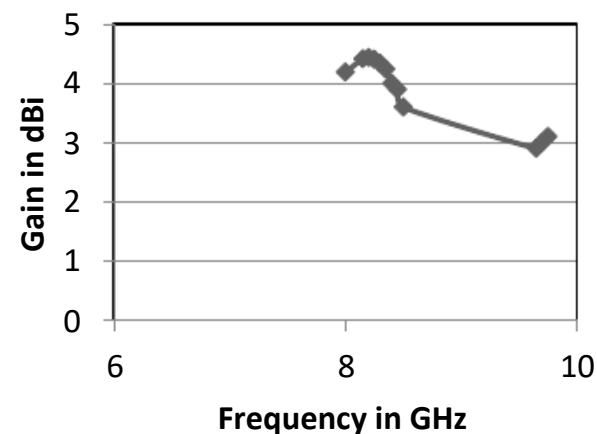

(b)

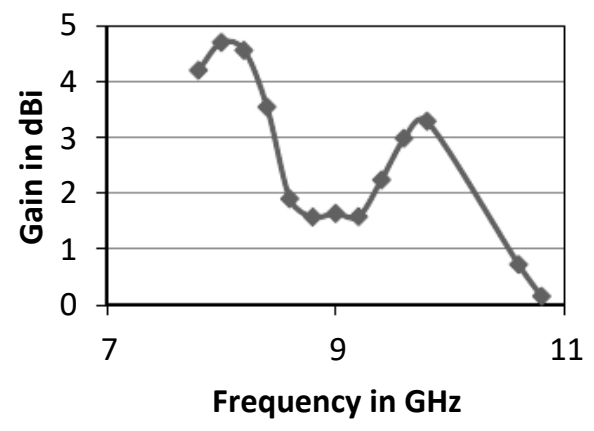

D

Figure. III: Frequency $(\mathrm{GHz})$ versus Gain $(\mathrm{dBi})$.

(a) Antenna I; (b) Antenna II; (c) Antenna III; and (d) Antenna IV

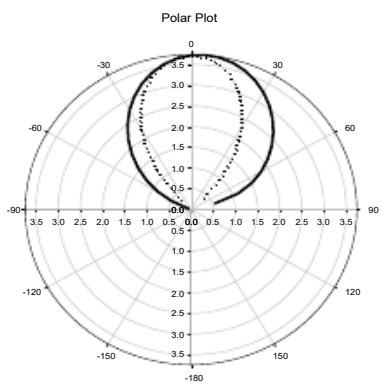

-

(a)

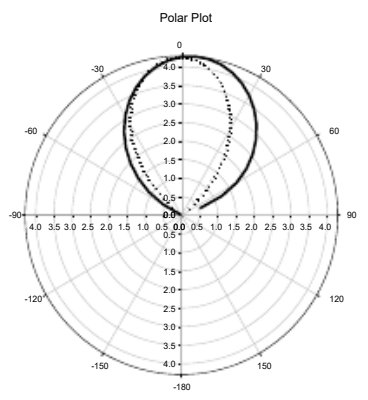

-

(d)

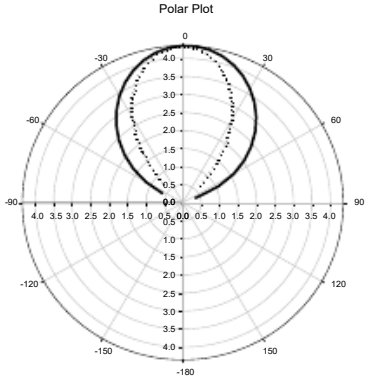

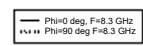

(b)

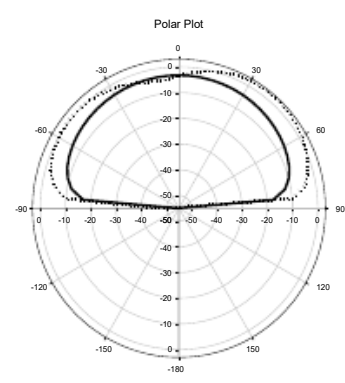

Find

(e)

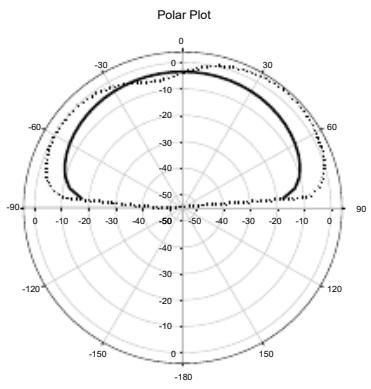

(c)

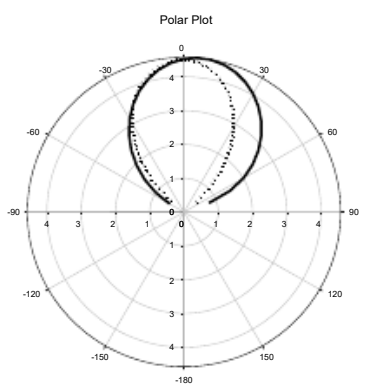

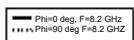

(f) 


\section{Susmita Bala}

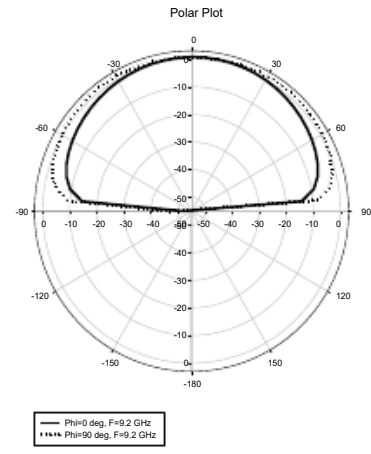

$(\mathrm{g})$

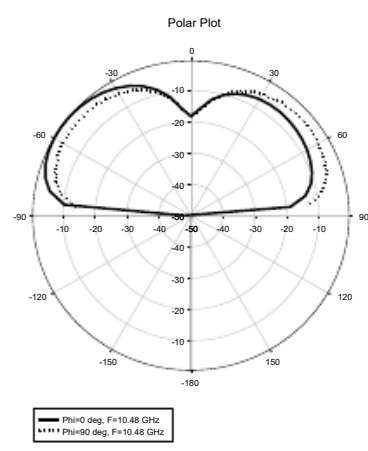

(h)

Figure. IV: Radiation patterns of the Antennas. (a) Antenna I at $5.2 \mathrm{GHz}$; (b) Antenna II at $8.3 \mathrm{GHz}$; (c) Antenna II at $9.7 \mathrm{GHz}$; (d) Antenna III at $8.2 \mathrm{GHz}$; (e) Antenna III at $9.8 \mathrm{GHz}$; (f) Antenna IV at $8.2 \mathrm{GHz}$; (g) Antenna IV at $9.2 \mathrm{GHz}$; and (h) Antenna IV at $10.48 \mathrm{GHz}$

\section{CONCLUSION}

A design of microstrip wideband antenna is proposed here. Impedance bandwidth of the proposed antenna has improved significantly by adding two rectangular parasitic patches with the main modified circular patch. As a result, a wide bandwidth from $7.86 \mathrm{GHz}$ to $10.60 \mathrm{GHz}$ for a return loss greater than $10 \mathrm{~dB}$ is achieved. The antenna provides peak gain of $4.56 \mathrm{dBi}$. Suitable radiation patterns are also obtained. These make the Antenna IV suitable for X band application.

\section{REFERENCES}

[1] G. Kumar, and K. P. Ray, Broadband Microstrip Antennas, (Norwood, MA: Artech House, Inc, 2003), 1-52.

[2] D. Aissaoui, L. M. Abdelghani, N. Boukli-Hacen, and T. A. Denidni, CPW-Fed UWB Hexagonal Shaped Antenna with Additional Fractal Elements, Microwave and Optical Technology Letters, 58 (10), 2016, 2370-2374.

[3] A. K. Gautam, S. Yadav, and B. Kr, A CPW-Fed Compact UWB Microstrip Antenna, IEEE Antennas and wireless Propagation Letter, 12, 2013, 151-154.

[4] J.U.R Kazim, S Ahmad, U Ali, and Owais, Design of a Broadband Planar Monopole MIMO Antenna, Microwave and Optical Technology Letters, 56(9), 2014, 1994-1997.

[5] A. Foudazi, H.R. Hassani, and S. M A. Nezhad, Small UWB Planar Monopole Antenna With Added GPS/GSM/WLAN Bands, IEEE Transactions On Antennas And Propagation, 60 (6), 2012, 2987-2992.

[6] D. Sharma and M.S. Hashmi, A Miniaturized Ultra Wideband monopole Antenna with Defected Ground, IEEE Annual India Conference (INDICON), Bangalore, India, 2016, 2325-9418

[7] A. Kandwal, R. Sharma and S. K Khah, Bandwidth Enhancement Using Z-Shaped Defected Ground Structure for a Microstrip Antenna, Microwave and Optical Technology Letters, 55(10), 2013, 2251-2254.

[8] E.Sivakumar, S.RO, A.V.M.Manikandan, Bandwidth enhancement of rectangular microstrip patch antenna using slots, IOSR Journal of Electronics and Communication Engineering (IOSR-JECE), 6(1), 2013, 07-10.

[9] P. B. Parmar, B. J. Makwana and M. A. Jajal, Bandwidth Enhancement of Microstrip Patch Antenna Using Parasitic Patch Configuration, International Conference on Communication Systems and Network Technologies, Rajkot, India 2012.

[10] Balanis CA. Antenna Theory, Analysis and Design (Ed. 2), (New Jersey: John Wiley \& Sons, Inc. 1997) 843-846. 
[11] R. Rashmi, K. P. Ray, S P. Duttagupta, Bandwidth Enhancement Using Gap-Coupled Hexagonal Microstrip Antennas In L Band, Microwave and Optical Technology Letters, 55(11), 2013, 2703-2709.

[12] P. Naveen Kumar, S. Chandramma, Ravi H. R, Kishan Singh, Nagaraja Kulkarni, S. N. Mulgi and P. V. Hunagund, A Novel Design and Development of Rectangular Microstrip Antenna for $\mathrm{C}$ to $\mathrm{Ku}$ Band Operation, International Journal of Electronics and Communication Engineering \& Technology (IJECET), Volume 6, Issue 4, April (2015), pp. 21-27

[13] P. Naveen Kumar, Ravi. H. R, S. Chandramma, Kishan Singh, Nagaraj Kulkarni, S. N. Mulgi and P. V. Hungund, A Novel Design and Evaluation of Rectangular Microstrip Antenna for Microwave Application, International Journal of Electronics and Communication Engineering \& Technology (IJECET), Volume 6, Issue 7, July (2015), pp. 01-07

[14] Dr. Nagraj K. Kulkarni, A Novel U-Slot Circular Microstrip Antenna for Triple Band Operation, International Journal of Advanced Research in Engineering and Technology (IJARET), Volume 5, Issue 2, February (2014), pp. 168-172

[15] L. Lolit Kumar Singh, Bhaskar Gupta and Partha P Sarkar, A Review on Effects of Finite Ground Plane on Microstrip Antenna Performance, International Journal of Electronics and Communication Engineering \& Technology (IJECET), Volume 3, Issue 3, October- December (2012), pp. 287-292

[16] Dr. Nagraj K. Kulkarni, Back Fed Top Ground Equilateral Triangular Microstrip Antenna for Quad Band Operation, International Journal of Advanced Research in Engineering and Technology (IJARET), Volume 5, Issue 2, February (2014), pp. 163-167

[17] Ravindra Kumar Yadav, Jugul Kishor and Ram. Lal Yadava, Compensation of Dielectric Cover Effects on Cp Hexagonal Microstrip Antenna, International Journal of Electronics and Communication Engineering \& Technology (IJECET), Volume 4, Issue 1, January- February (2013), pp. 43-54

[18] Dr. Nagraj K. Kulkarni, Complementary Symmetry E-Slot Rectangular Microstrip Antenna for Triple Operation, International Journal of Electronics and Communication Engineering \& Technology (IJECET), Volume 5, Issue 3, March (2014), pp. 13-17

[19] Dr. Nagraj K. Kulkarni, Complementary Symmetry Rectangular Microstrip Antenna for Triple Wideband Operation, International Journal of Advanced Research in Engineering and Technology (IJARET), Volume 5, Issue 3, March (2014), pp. 37-41

[20] Dr. Nagraj K. Kulkarni, Complementary Symmetry U-Slot Equilateral Triangular Microstrip Antenna for Penta Band Operation, International Journal of Advanced Research in Engineering and Technology (IJARET), Volume 5, Issue 3, March (2014), pp. $42-46$

[21] Nagraj Kulkarni and S. N. Mulgi, Corner Truncated Inverted U - Slot Triple Band Tunable Rectangular Microstrip Antenna for WLAN Applications, International Journal of Electronics and Communication Engineering \& Technology (IJECET), Volume 3, Issue 1, January- June (2012), pp. 01-09

[22] M. Veereshappa and S. N. Mulgi, Corner Truncated Rectangular Slot Loaded Monopole Microstrip Antennas for Quad-Band Operation, International Journal of Electronics and Communication Engineering \& Technology (IJECET), Volume 4, Issue 2, March - April, 2013, pp. $165-171$

[23] Suryakanth B and Shivasharanappa N Mulgi, Design and Development of Low Profile, Dual Band Microstrip Antenna with Enhanced Bandwidth, Gain, Frequency Ratio and Low Cross Polarization, International Journal of Electronics and Communication Engineering \& Technology (IJECET), Volume 1, Issue 1, Sept-Oct (2010), pp. 88-98.

[24] M. Veereshappa and Dr. S. N Mulgi, Design and Development of Triple Band Ominidirectional Slotted Rectangular Microstrip Antenna, International Journal of Electronics and Communication Engineering \& Technology (IJECET), Volume 3, Issue 1, January- June (2012), pp. 17-22

[25] Sudhanshu Mathur and Ushma Sharma, Design and Implementation of Double Face P Shaped Microstrip Antenna for Wireless Application. International Journal of Electronics and Communication Engineering and Technology, 8(4), 2017, pp. 31-34. 